\title{
Investigating retention and workplace implementation of board game learning in employee development
}

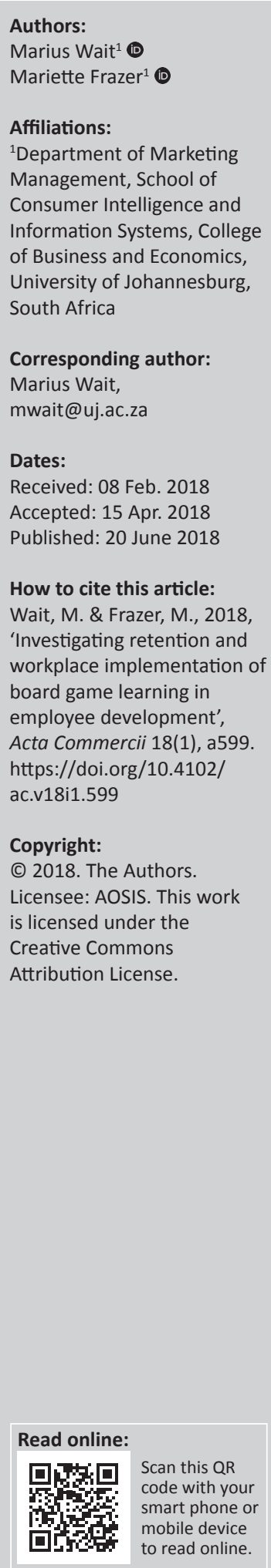

Orientation: Business simulation games for the development of learners take many forms, such as video games and computer games, and are popular choices in academia. The board game, however, is an underutilised educational tool in the development of employees.

Research purpose: The retention of board game learning long after the intervention, and the workplace implementation of the decisions it has involved, is an area neglected by academia.

Motivation for the study: This study wanted to determine if board games are an effective teaching tool by investigating retention and workplace learning of board games.

Research design, approach and method: This qualitative study used descriptive interpretation and deductive content analysis based on two group interviews conducted 1 year after the board game was played.

Main finding: This study showed that the participants retained and implemented the learning long after the board game intervention. It is a practical, interactive way to encourage teamwork and allows participants to learn and implement decisions.

Practical and managerial implications: Company executives should consider board games as an alternative to traditional educational methods of developing employees.

Contribution or value-add: This study showed overwhelmingly that employees still remember the board game 1 year after the intervention and implemented some of its learning in the workplace.

\section{Introduction}

Corporate training and continuing adult education have increased in importance owing to substantial changes in many areas of life, including the dynamic growth of industry and its complexities and a competitive marketplace (Kum, Cowden \& Karodia 2014:79; Masalimova, Usak \& Shaidullina 2016:1480). Business schools are recognising the need to make courses relevant to the student's future employment by incorporating skills and knowledge. Problem-solving skills in particular are needed for future leadership. Business schools develop these skills through the design and implementation of innovative learning methods and pedagogy. These innovative ways of learning have moved away from a traditional didactic model of instruction to a learnercentred model that places learners in a more active role through which they learn by doing (Pratt \& Hahn 2016:10). One such innovative tool is game-based learning (GBL). Herro and Clark (2016) state that GBL has influenced the research agenda, as is evident from the large number of hubs focusing on designer games and simulation for the educator, such as Games+Learning+Society (www.gameslearningsociety.org), The Centre for Games and Impact (http://gamesandimpact.org) and Education Arcade (http://education.mit.edu). However, these hubs and GBL research have focused on video and online games and not board games for higher education. Treher (2011) is of the opinion that although board games have already been used in the corporate setting for a while, their value and impact are generally unrecognised. Board games developed for educational purposes are being incorporated into the learning process of corporate training. As the theory and mechanics of board games have evolved, opportunities for their meaningful application in board game learning (BGL) have increased. Bell and Loon (2015:120) opine that playing simulation games affects development in two respects: it provides a teaching framework in which participants make decisions to achieve their final goal, taking into consideration how other participants' decisions affect their own, and it reinforces learning through the continuous feedback obtained from such decision-making. Pando-Garcia, Periañez-Cañadillas and Charterina (2016:1732) state 
that business games all differ but share common features: decision-making, overview, target-based orientation and a focus on problem-solving.

Treher (2011:8) states that our current interactive, technologybased world has enabled learning to be achieved by means other than the lecture. The days are gone when adults were expected to sit and listen to long lectures as part of their development. Incorporating interactive board games opens the learning window and provides entertaining and easy methods to collect formative assessment data. Employees have been found to retain enough knowledge after a board game to be successful in their job and demonstrate greater understanding of its challenges (Treher 2011:6).

Although the application of simulation games in various forms has grown in education, limited research has been conducted on the retention and workplace implementation of BGL, which is the research aim of this study, especially as an employment development tool. This article aims to explore the following aspects of this issue: participants' experience of BGL as an educational tool, the learning that participants retained from the experience, how they applied this learning in their workplace, how their understanding of the workplace improved through BGL and whether their confidence levels remained high after playing the board game.

This introduction provides a general background to the research topic and is followed by a literature review on board games as an educational tool, its effect on employees' confidence and workplace implementation of the learning achieved. The research methodology, which included two group interviews and qualitative deductive content analysis, is then explained. This is followed by the presentation and discussion of results, and the article ends with managerial implications and a conclusion.

As this study was conducted in a corporate environment with particular reference to employee development, it includes concepts of corporate training, employee training, job training and adult education within the concept of employee development.

\section{Literature review Board games as an educational tool}

A game is defined as any contest (play) among adversaries (players) operating under constraints (rules) for an objective (winning, victory or some sort of pay-off) (Khan \& Pearce 2015:194). Pratt and Hahn (2016:11) state that a simulation game is a specific sequence of real-life activities designed to convey lessons to the participant based on the properties of a real-world situation.

Doyle and Brown (2000:331) compared traditional teaching methods with game learning and found the following: games are used to support learning, and learners are more active participants in this process than they are in lectures. All players who play the game conscientiously learn substantially; the more they participate, the more they will learn. Like the case study, a game represents a snapshot of a hypothetical company's situation at a given moment. Compared to role-play, games provide more interaction because of the teamwork aspect.

Game-based learning, as a broad category, has made significant strides over the past 10 years, emerging as a powerful educational tool that can affect students positively. Several studies have evaluated the impact of game learning in a variety of disciplines such as mathematics, science, language, geography and computer science. All these studies show positive outcomes in student motivation and learning effectiveness (Sardone \& Devlin-Scherer 2016:215). However, literature research by Wait and Frazer (2017) found that BGL entails a research dilemma when it comes to the correct naming of this educational tool. The concept of GBL includes board games, card games, mobile games and video games. Some researchers prefer the concept of simulation games, which tend to focus mainly on video games. Most of the research into games as an educational tool focuses on computer and video games. This is acknowledged by Khan and Pearce (2015:193), who identify blended learning, gaming, simulations, board games and a variety of other interventions as new methods of generating learning experiences that can enhance learning for the future university. These diverse terms could create confusion, but in this study the term 'BGL' denotes a specific educational tool, as proposed by Wait and Frazer (2017). Board game learning falls under the umbrella of GBL.

Treher (2011:2) laments the fact that although board games in the corporate world have gained a foothold, most research on board games focuses on young children. The reason may be that many company executives do not understand how learning happens and have a grudging attitude to corporate training, seeing it as a financial drain and an intrusive time away from work (Kum et al. 2014:72). Board games are an important educational tool that provides hands-on and heads-on skills and knowledge. This type of learning provides a non-threatening, playful and competitive environment in which to reinforce learning and apply its content. The board in the board game provides a visual metaphor that helps participants to connect with the information. The game elements, discussion of the players and problem-solving all provide vehicles for learning. This idea is shared by Zhang (2015:154), who states that the experience derived from simulation games offers unique learning benefits that allow for students to develop critical management skills. Simulation games can also be seen as a form of experiential learning in which students practise their developing, implementing and controlling skills and make complex, functional, integrated decisions in a competitive environment that reflects real life. This hands-on learning helps to bridge the gap between classroom and real-world situations. Gibson and Douglas (2013:612) state that board games can help students engage 
with course content. Khan and Pearce (2015:193) opine that board games can involve a variety of students with different learning styles. Pando-Garcia et al. (2016:1732) state that business simulation games have several benefits: they allow the student to address educational content in a more enjoyable and interactive way, they can address content that is difficult to represent via other methodologies, they provide learners with the possibility of acquiring management skills and competencies that are necessary in the business world and they help learners to gain experience without the financial risks of implementing their decisions in the real world.

\section{Retention of learning}

Learners remember more when they practise or use the learning compared to when they just read or hear the information. The amount of information remembered is in direct proportion to the amount of involvement in the learning process (Northwest Center for Public Health Practice 2015:15). Adams and Ewen (2009:3) agree, saying that the retention of learning material is systematically related to 'how sure' students are about the correctness of their answers. In other words, if students are 'not sure' if their answer is correct, they will retain and apply only about $25 \%$ of the learning 1 week later. If students are 'extremely sure' about their answer, they will retain and apply about $91 \%$ of the learning. Spivey (2016:1-2) states that learning retention is a primary concern in adult education, and there are several proposed strategies to address this. One such strategy is to understand that adults learn differently from younger students. Academia calls this andragogy, the art and science of adult learning; it refers to any form of adult learning, as opposed to pedagogy, which refers to child learning (Pappas 2013). The cone of learning shows that we tend to remember less of what we read and more of what we do (Figure 1).

The cone of learning concept is endorsed by Sardone and Devlin-Scherer (2016:215), who opine that game playing has a positive effect on brain activity, stimulating more learning retention and engaging players towards more effective understanding compared to traditional class instruction.

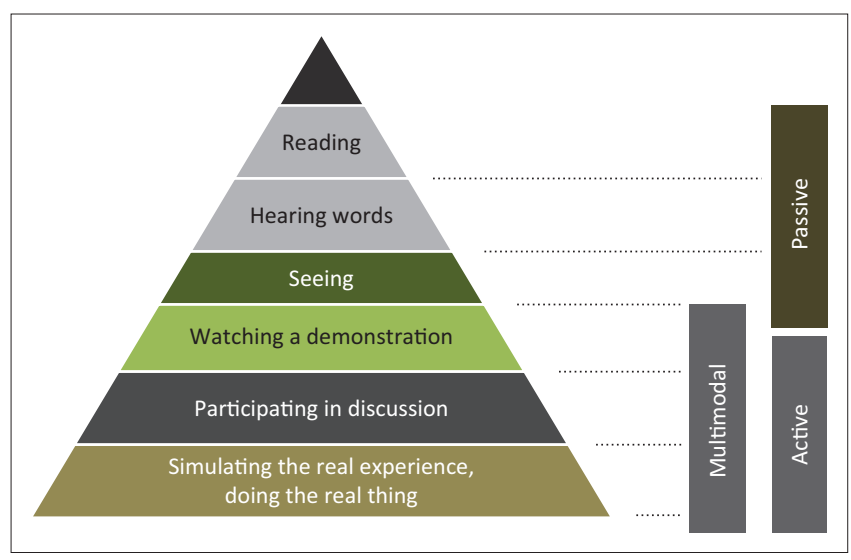

Source: Northwest Center for Public Health Practice, 2015, Effective adult learning: A toolkit for teaching adults, NWCPHP, University of Washington School of Public Health, Washington DC, p.15

FIGURE 1: The cone of learning.

\section{Workplace implementation of learning}

The ultimate goal of workplace learning is the implementation of new skills in the work environment. Playing games as an educational tool can be useful for students as they acquire skills which may not otherwise be taught. Games sharpen the players' entrepreneurial skills as they learn to deal with incomplete information, predict rivals' strategy and understand human psychology (Khan \& Pearce 2015:193). Kum et al. (2014:76) also refer to workplace implementation of learning as a transfer of learning from the classroom to the workplace, and they mention several factors that can prevent workplace implementation of training.

\section{These include the following:}

- Whether employees see any value in applying the new skills, or if there is no reward as a result of implementation or the value of the reward is low.

- Whether employees have little room to change work tasks; in other words, whether the job is too tightly controlled.

- Whether the employee's line manager is in favour of training; line managers exert a powerful influence over employees and may control rewards as punishment.

- Whether fellow employees view workplace changes with scepticism.

Kum et al. (2014:78) continue and state that the workplace implementation of training must lead to an increase in quality goods and services and fewer mistakes. Accordingly, accuracy, effectiveness, good work, safety practices and good customer service can be expected. As this is a neglected research area, limitations of BGL are not evident.

\section{Employee development and confidence in the workplace}

The development of employees and their professional skills and professional qualities constitutes major conditions for improving and maintaining the competiveness of the modern enterprise (Masalimova et al. 2016:1480). Vuţă and Fărcaş (2015:368) agree and state that adult education and training is a prerequisite for employees' careers and personal development. The acquisition of knowledge and skills helps to improve the employees' place in the workplace and the labour market and will lead to an increase in productivity. Employee development is designed to develop not only knowledge, skills and abilities but also work-related skills, defined as functional skills of vocational origin that are formative and experiential in nature and useful in specific situations. Adam and Ewen (2009:1) lament that one of the most important questions in education is how to enable students to apply the learning to perform tasks quickly, confidently and reliably. Retention of learning is systematically related to 'how sure' students are about the correctness of their knowledge when they learn it. In other words, confidence and knowledge are correlated and both should be determinants of future performance. The more confident students are in their knowledge, the more likely it is that they 
will display confidence. High confidence levels are associated with true knowledge. Bell and Loon (2015:121) state that game learning provides the opportunity to develop higher order thinking skills through the development of critical and strategic thinking skills, which are particularly useful in teaching general management skills. Pando-Garcia et al. (2016:1732) agree and state that business games enable simulation of decision-making that is involved in managing a business, thus strengthening the participants' management skills. Better confidence levels improve the motivation and morale of employees, which is key to retaining staff.

\section{Research methodology and design}

In order to investigate learning retention and workplace implementation of BGL, the opinions of adult learners were gauged one year after they had played the board game as part of their workplace development programme. The target population for this BGL study was retail store employees at various levels of management and with various levels of experience. A brief description of the board game used for this study follows.

The design of the board game rests on constructivist andragogy, which allows the participant to construct knowledge and draw on existing knowledge in an idiosyncratic way while working in a group. The board game used for this study can be played with four to six teams of three to four members each. Each team uses workbooks and a simulation board with various markers that represent the money (cash and debtors), non-current assets, liabilities (loans and creditors), staff and stock in the business. Each team starts off at the same point, having a running retail concern with six retail outlets already in operation and the same financial and market share position. The teams allocate various business roles to the team members in terms of marketing, operations, finance, human resources and general management. The business and decision-making processes of the game are explained by a qualified facilitator. This facilitator also acts as the supplier of market research, stock and banking services, and teams have to negotiate with the facilitator in the same manner as in a real-life situation.

The teams play two cycles that include three rounds each. The teams are required to make market-related decisions, which are then entered into a computer model that divides the available market share between the teams. This is calculated on the basis of comparing the teams' product sales, stock levels, customer service levels and promotion spend. At the end of the game, the results are compared on a group basis (Wait \& Frazer 2017).

\section{Research instrument}

This study used a descriptive design, working through the text with a deductively formulated category system, and the deductive content analysis procedural model of Mayring (2014:96) as illustrated in Figure 2.

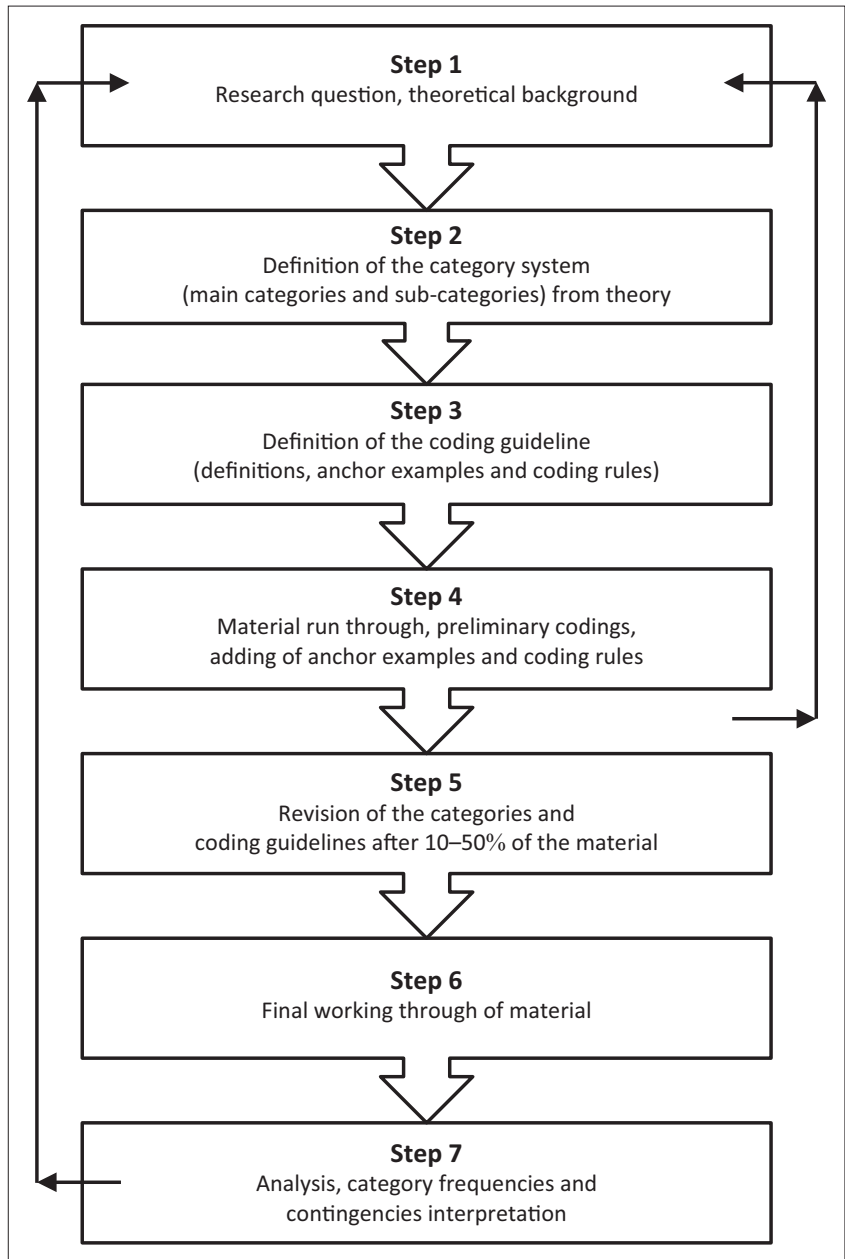

Source: Mayring, P., 2014, 'Qualitative content analysis: Theoretical foundation, basic procedures and software solution', viewed 30 January 2018, from http://nbn-resolving.de/ urn:nbn:de:0168-ssoar-395173, p. 96

FIGURE 2: Procedural model of research methodology followed.

Step 1: Research question. Formulate a clear research question and describe the theoretical background. The theoretical underpinning must fit the ongoing deduction. For this study, the research aim is 'to explore retention of learning and workplace implementation of board game learning'. Step 1 is covered in the introduction and literature review sections.

Step 2: Definition of categories. The research question has to be operationalised into categories, in other words into research aspects that are taken to the research sample. The state of the research subject and previous studies on the topic must be analysed to get a theoretical foundation. Not all categories may be found in the literature, but categories have to be grounded with theoretical arguments. For this study, the research objectives are to explore the following aspects of the issue: participants' experience of BGL as an educational tool, the learning that participants retained from the experience, how they applied this learning in their workplace, how their understanding of the workplace improved through BGL and whether their confidence remained high after playing the board game. Step 2 is covered in the introduction and literature review sections and in the recorded and transcribed group interviews - the text. The five research objectives formed the group interview protocol. The group interview 
participants were randomly selected from a list of employees who had successfully completed the board game. There were 10 participants in each of the two group interviews. The units of analysis were the recorded and transcribed interviews.

Step 3: Coding guidelines. The various categories - in this case, the research objectives - are defined and explained in order to ease text coding. Coding guidelines and rules are set. This step is needed to ease the matching of text to categories.

Step 4: Coding. The text is read and relevant sections coded. Text that matches the category definition is coded and recorded. When text is found that does not match the categories accurately or is unclear, a new coding rule should be considered.

Step 5: Revision. This step is done after $10 \%-50 \%$ of the text has been coded. The coding rules and category definitions are checked.

Step 6: Final work through. The text is worked through and coded into categories.

Step 7: Analysis. Frequencies of codes are statistically analysed.

Deductive content analysis is most central to qualitative research. It has the goal of extracting certain structures from the text. The categories under investigation are deduced from theory, other studies of previous research. In other words, research aspects are taken to the research data and coded accordingly (Mayring 2014:97).

\section{Ethical considerations}

The research was conducted according to ethical principles such as ensuring the confidentiality and anonymity of participants. Participants were asked to volunteer to be part of the research and could withdraw at any time. The participants were not part of any vulnerable groups. The privacy of the respondents was respected and not put under any social, physiological or physical risks during the collection of the data.

\section{Results and discussion}

The views below have been derived mainly from the analysis of the group interview research material and are formulated to reflect the main themes which emerged. All the participants still remembered the board game in their curriculum, even after a year, and their experience of the board game was overwhelmingly positive. The two group interviews, with direct quotations, will be distinguished by referring to Group 1 and Group 2.

The respondents all agreed that their experience of the board game had been very advantageous. Both groups brought up the issue of improvement in decision-making. Group 1: 'It made you think before making a decision'. Group 2: 'The board game helped us to understand the decisions we make in store'. Another major issue brought up by both groups was that of 'other departments'. Group 1: 'The linkages to other departments are clearer and my decisions affect those departments'. Group 2: 'I understand other departments better'. The improvement of decision-making skills and understanding of the bigger picture link with the findings of Sardone and Devlin-Scherer (2016:215), who state that immersive experiential learning environments like those involved in games draw students in and enhance their ability to process information, make decisions, apply knowledge, solve problems and collaborate. Avramenko (2011:357) agrees and states that simulation games assist in enhancing critical management thinking skills.

In the category of learning retained from the board game, the vast majority of the students in both groups felt that they had indeed retained learning, and they brought up the issue of finances, agreeing that they were far more finance savvy after the board game. Group 1: 'I understand finance much better'. Group 2: 'I learned that capital investment is much better than money in the bank'. This finding ties in with the finding of Khan and Pearce (2015), who state that playing games can be useful for students as they acquire skills that may not otherwise be taught. Avramenko (2011:357) states that games are effective in improving quantitative skills. Leger (2006:12) agrees, saying that analysis of the financial results of participants after a game is enlightening with respect to the learning process involved.

When participants were asked to provide examples of how they applied their learning in the workplace, the vast majority in both groups mentioned the connection between stock and finances. Group 1: 'Spending money on the right stock has a positive effect on the balance sheet'. Group 2: 'I did a promotion on the stock that is not moving, so I made money for my company'. Kum et al. (2014:74) agree with this finding and state that if the training and development of employees are executed correctly, the effects on employees' performance often encourage growth in the employer and the organisation itself. Vuţă and Fărcaş $(2015: 368,369)$ also confirm this finding and state that employee development becomes important in contributing to workplace transformation and results in the development of workplace initiatives.

All the participants felt that they had gained a better understanding of their workplace after the board game. Group 1: 'I was reluctant to make decisions and scared to execute them, but now that I understand business better, my decisionmaking is easier and I'm always anxious to see if they work'. Group 2: 'Yes, I understand each department better, even HR, and how they are working'. Avramenko (2011:361) states that business simulation games help participants to be mindful of the interrelatedness of the main business functions: marketing, operations, HR and finance. Games also improve participants' understanding of essential management elements.

All the participants felt that their confidence levels had improved after the board game and had stayed high, even long after the board game. In general, the findings from the participants' feedback were encouraging. The retention of learning and the workplace implementation of BGL had 
boosted morale, as participants felt that their confidence and their financial and business decision-making skills had improved after the board game and been retained after a year. During the coding of the research text, improvements in financial and decision-making skills were the two topics that the participants mentioned most. The participants had implemented some of the BGL in their workplace and been able to witness the positive effect of this.

\section{Managerial implications}

The current methods of developing employees need to be challenged in respect of learning retention and workplace implementation of learning. If managers want employees to analyse business situations from different perspectives and to derive optimal solutions, board games must be a consideration in employee development. Management needs to consider the practical implementation of the skills they want to train employees to acquire, and the method used should simulate the real work environment as closely as possible. Furthermore, some methods yield better retention and implementation than classroom training, and the value of these interventions needs to be considered when training methods are selected. In many cases, training is conducted in the faith that it will lead to better performance in the workplace, but there is no intervention to test if this is true. Management should therefore consider putting appropriate measures in place to determine the true effect of training.

Board game training allows for training to be targeted at a specific skill in a specific field, making it easier for participants to relate to relevant concepts and later implement them in the workplace. Board games also allow students to see the bigger picture and how different departments within organisations need to function together to deliver a desired outcome. Furthermore, learning through play allows participants to overcome fear of difficult concepts such as finance and to break down complex concepts into chunks that are easy to understand. Therefore, the board game is a convenient tool with which management can approach training from a different perspective.

\section{Limitations}

This study was conducted in only one industry sector, namely retail, and took place in Johannesburg, South Africa. The results cannot be generalised.

\section{Conclusion}

Business simulation games come in many forms, such as video games, computer games and mobile games. Properly designed board games in the corporate classroom have proven their unique value in providing confidence, empowering, encouraging and educating. This study focused on BGL as an educational tool in the development of employees, with special reference to the retention and workplace implementation of learning after this intervention. Much literature is available on the general benefits of business simulation games, and there is much evidence of the improvement they make in participants' decision-making and general management skills. This study indicated that the learning was retained and could be implemented in the workplace even after a year and that participants could apply theory to practice.

Board games provide cost-effective resources in that they summarise and reinforce information in a format that is easy to grasp. A board game can reduce the time needed to learn, remember and apply new learning. It can also promote discussion, collaboration and improved communication. Board games should be seen as experiential learning exercises through which students can practise developing, implementing and controlling strategies and the making of complexand functionally integrated decisions in an environment that reflects real life.

Board games provide more measurable results than classroom training. This being said, it is important to conduct posttraining interventions that measure the effectiveness of all types of training to determine the return on investment, as the ultimate goal is to increase the effectiveness of the organisation at all levels.

\section{Acknowledgments Competing interests}

The authors declare that they have no financial or personal relationships that may have inappropriately influenced them in writing this article.

\section{Authors' contributions}

Both authors have worked as a group. The participants were obtained from M.F.'s class, but both M.W. and M.F. were present during the group interviews. The literature review was divided up into various tasks, which were undertaken by both M.W. and M.F.

\section{References}

Adam, T.M. \& Ewen, G., 2009, 'The importance of confidence in improving educational outcomes', Paper presented at the 25th Annual Conference on Distance Teaching and Learning, Monona Terrace, University of Wisconsin-Madison, 03 August, viewed 30 January 2018, from https://pdfs.semanticscholar.org/d2b3/e69ed19 e3432375b9be8a09e08d3cab5ffca.pdf

Avramenko, A., 2011, 'Enhancing students' employability through business simulation', Education and Training 54(5), 355-367. https://doi.org/10.1108/00400911211 244669

Bell, R. \& Loon, M., 2015, 'The impact of critical thinking disposition on learning using business simulations', The International Journal of Management Education 13, 119-127. https://doi.org/10.1016/j.ijme.2015.01.002

Doyle, D. \& Brown, F., 2000, 'Using a business simulation to teach applied skills - The benefit and the challenges of using student teams from multiple countries' Journal of European Industrial Training 24(6), 330-336. https://doi.org/10.1108/ 03090590010373316

Gibson, V. \& Douglas, M., 2013, 'Criticality: The experience of developing an interactive educational tool based on board games', Nurse Education Today 33, 1612-1616. https://doi.org/10.1016/j.nedt.2013.01.022

Herro, D. \& Clark, R., 2016, 'An academic home for play: Games as unifying influences in higher education', On the Horizon 24(1), 17-28. https://doi.org/10.1108/OTH08-2015-0060

Khan, A. \& Pearce, G., 2015, 'A study into the effects of a board game on flow in undergraduate business students', The International Journal of Management Education 13(3), 193-201. https://doi.org/10.1016/j.ijme.2015.05.002

Kum, F.D., Cowden, R. \& Karodia, A.M., 2014, 'The impact of training and development on employee performance: A case study of ESCON consulting', Singapore Journal of Business Economics and Management Studies 3(3), 72-105. https://doi.org/ 10.12816/0010945

Leger, P., 2006, Using a simulation game approach to teach ERP concepts, Series: Cahier du GReSI, Paper no. 06-02, Québec, HEC Montréal, pp. 1-15. 
Masalimova, A.R., Usak, M. \& Shaidullina, A.R., 2016, 'Advantages and disadvantages of national and international corporate training techniques in adult education', Current Science 111(9), 1480-1486. https://doi.org/10.18520/cs/v111/i9/1480-1485

Mayring, P., 2014, 'Qualitative content analysis: Theoretical foundation, basic procedure and software solution', viewed 30 January 2018, from http://nbn-resolving.de/ urn:nbn:de:0168-ssoar-395173

Northwest Center for Public Health Practice, 2015, Effective adult learning: A toolkit for teaching adults, NWCPHP, University of Washington School of Public Health Washington, DC

Pando-Garcia, J., Periañez-Cañadillas, I. \& Charterina, J., 2016, 'Business simulation games with and without supervision: An analysis based on the TAM model', Journal of Business Research 69, 1731-1736. https://doi.org/10.1016/j.jbusres. 2015.10.046

Pappas, C., 2013, The adult learning theory - Andragogy - Of Malcolm Knowles, viewed n.d., from https://elearningindustry.com/the-adult-learning-theory-andragogy-ofmalcolm-knowles

Pratt, M.A. \& Hahn, S., 2016, 'Enhancing hospitality student learning through the use of a business simulation', Journal of Hospitality, Leisure, Sport \& Tourism Education 19, 10-18. https://doi.org/10.1016/j.jhlste.2016.05.001
Sardone, N.B. \& Devlin-Scherer, R., 2016, 'Let the games begin: Creative ways to enhance teaching and learning', The Clearing House 89(6), 215-222. https://doi. org $/ 10.1080 / 00098655.2016 .1214473$

Spivey, T.M., 2016, 'Examining barriers to retention of adult learners in rural educational programs', Doctoral study, Walden University, Minneapolis, viewed December 2017, from http://scholarworks.waldenu.edu/cgi/viewcontent.cgi?article=3299\&context= dissertations

Treher, E.N., 2011, Learning with board games: Play for performance, viewed December 2017, from https://www.thelearningkey.com/pdf/Board_Games_TLKWhitePaper_ May16_2011.pdf

Vuţă, D.R. \& Fărcaş, A., 2015, 'The role of training in organizational and employee development', Revista Academiei Fortelor Terestre 20(3), 367-372.

Wait, M. \& Frazer, M., 2017, 'The effectiveness of board game learning as an educational tool in employee development', Paper presented at GBATA 2017: The 19th Annual International Conference of the Global Business and Technology Association, Vienna, 11-15th July.

Zhang, M.J., 2015, 'Using login data to monitor student involvement in a business simulation game', The International Journal of Management Education 13, 154-162. https://doi.org/10.1016/j.ijme.2015.02.003 